\title{
The effect of the initial elemental abundance on gas-grain chemical models
}

\author{
O. M. Shalabiea ${ }^{1,2, \star}$ \\ 1 Astronomy Program, SEES, Seoul National University, Seoul 151-742, Korea \\ 2 Department of Astronomy, Cairo University, Cairo, Egypt
}

Received 27 October 2000 / Accepted 16 February 2001

\begin{abstract}
For any chemical modeling, it is important to recognize that the adopted set of initial elemental abundances is a crucial parameter. The effect of initial abundance variation has been investigated. Using the most recent observations and theoretical grain models, we have set some constraints upon the set of the initial elemental abundances. Both gas-phase and gas-grain chemical models are used in this study. At early-time stages less than $1 \mathrm{Myr}$, there is little difference between results with different initial $[\mathrm{C}] /[\mathrm{O}]$ ratios. This holds for gas-phase and gas-grain models. At a later evolutionary time or in the steady state, the result of the gas-grain model shows little or no dependence on the initial $[\mathrm{C}] /[\mathrm{O}]$ ratios. By contrast, at late or steady-state times, the abundances of chemical species using gas-phase models are very sensitive to any variation of the initial $[\mathrm{C}] /[\mathrm{O}]$ ratios. Sulfur depletion is needed for both gas-phase and gas-grain models to reproduce the observed sulfur-bearing molecules. Our main conclusion is that the gas-grain interaction processes such as accretion, surface reactions, and desorption minimize the vital role of the initial set of elemental abundance in gas-grain chemical models.
\end{abstract}

Key words. molecular processes - ISM: abundances, clouds, molecules - Dust

\section{Introduction}

During the last decade, chemical models have progressed noticeably. Many of the key rates of reactions have been improved in the gas-phase. Also gas-grain interactions have been given more attention, showing their crucial role in chemical models (Hasegawa et al. 1992; Willacy \& Williams 1993; Shalabiea \& Greenberg 1994; Shalabiea et al. 1998; Willacy \& Millar 1998; Ruffle \& Herbst 2000, 2001). However after years of extensive theoretical, experimental, and observational studies, interstellar chemical modeling still has many puzzling problems.

One of these problems is the set of the adopted gasphase elemental abundances with which the reactions network starts to operate. There are three aspects to this problem of particular interest. The first is the carbon-tooxygen ratio $[\mathrm{C}] /[\mathrm{O}]$, the second is the sulfur depletion and the third is the depletion of heavy elements. These aspects and their implications for chemical models are discussed in more detail in Sect. 2. The problem related to the adopted set of elemental abundances exists in both gas-phase and gas-grain chemical models. Several authors (e.g. Watt 1985; Terzieva \& Herbst 1998) have studied its effects on gas-phase models in Galactic molecular clouds. Millar \& Herbst (1990) have investigated gas-phase chemical models appropriate to the Magellanic clouds which have dif-

* e-mail: Osama@sci-astro.cairo.eun.eg ferent C, N, O abundances from our Galaxy. However, the effects of varying the elemental abundances on gas-grain models have not yet been investigated.

The main objectives of the present work are (1) to put some constraints on the adopted set based on the most recent observations of interstellar clouds and theoretical grain models, (2) to investigate how sensitive the gas-grain models are to initial elemental abundance variation compared with the gas-phase models, and (3) to study under which initial conditions and sets of elemental abundance, the results agree with the observations.

The layout of this paper is as follows: in Sect. 2 constraints on the initial elemental abundances are discussed. The chemical models and initial conditions we have used are described in Sect. 3. The results and discussion are presented in Sect. 4 and the conclusions are given in Sect. 5 .

\section{Constraints based on observations and grain models}

The observed abundances of different atomic elements in the interstellar medium (ISM) tend to be lower than those adopted as the cosmic (solar) reference standard, which is generally observed for the solar system (the solar photosphere or meteorites). This under-abundance (depletion) is traditionally interpreted as the varying degree of incorporation of these elements into dust grains. Substantial 
amounts of elemental depletion may result from the efficient formation of refractory grain materials. C, O, N, $\mathrm{S}$, and metals such as $\mathrm{Fe}, \mathrm{Si}, \mathrm{Mg}$ are among the most abundant elements, which commonly condense to form the solids of interstellar grains. The level of their depletion depends on the physical conditions in their environment.

\subsection{The carbon-to-oxygen ratio $[C] /[O]$ problem}

In earlier models it was found that the use of $[\mathrm{C}] /[\mathrm{O}]$ $>1.0$ is necessary to explain the abundance of carbonbearing species (Graedel et al. 1984; Langer et al. 1984; Herbst \& Leung 1986). At that time, Langer \& Graedel $(1987,1989)$ found that there are inconsistencies between the models and the observations for values of the $[\mathrm{C}] /[\mathrm{O}]$ ratio both greater and less than one. In the $[\mathrm{C}] /[\mathrm{O}]>$ 1.0 case they could explain the carbon abundance but not the $\mathrm{CN}$, which was too large in this model, while, in the $[\mathrm{C}] /[\mathrm{O}]<1.0$ case there was too much $\mathrm{O}_{2}$ and $\mathrm{H}_{2} \mathrm{O}$ in the results. Herbst \& Leung (1989) preferred to once again use a $[\mathrm{C}] /[\mathrm{O}]$ ratio less than one. This was mainly because the use of $[\mathrm{C}] /[\mathrm{O}]>1$ leads to overproduction of hydrocarbon species at steady state coupled with severe underproduction of oxygen-containing species such as methanol. In order to produce non-oxygen-bearing molecules effectively, Bettens et al. (1995) found that they needed values of $[\mathrm{C}] /[\mathrm{O}]>1$. In modeling the chemistry of giant molecular cloud cores, Bergin et al. (1997) found that the increase of $[\mathrm{C}] /[\mathrm{O}]$ ratio from 0.4 to 0.8 improves the agreement between their early-time calculations and the observed values. Pratap et al. (1997) studied the physical and chemical conditions along the TMC-1 ridge. They found that one method of reproducing the observed abundances is to vary the $[\mathrm{C}] /[\mathrm{O}]$ ratio slightly from 0.4 to 0.5 at early times.

The effects of a carbon-to-oxygen ratio variation have been extensively studied for gas-phase models of dense interstellar clouds by Terzieva \& Herbst (1998). The $[\mathrm{C}] /[\mathrm{O}]$ ratio was varied between 0.42 and 1.2 . Their best agreement with observations for L134N at steady state appears to be for $[\mathrm{C}] /[\mathrm{O}]$ between 0.6 and 0.8 . They also conclude that in their gas-phase model some of the molecules are not produced efficiently under most circumstances.

From the observational point of view, the fractional abundance of molecular hydrogen is often used as an indicator of the physical and chemical conditions in the ISM. The ratio of $\mathrm{C}$ to total hydrogen, $[\mathrm{C}] /[\mathrm{H}]$, has been known to remain constant over the observed range of $\left[\mathrm{H}_{2}\right] /[\mathrm{H}]$ (Cardelli et al. 1996; Sofia et al. 1997). Such a lack of variations suggests that additional depletion of gas-phase carbon by accretion onto dust does not occur in dense, molecule-rich clouds. Sofia et al. (1998) in their re-analysis of the carbon abundance in the translucent cloud toward HD 24534 (X Persei) found $[\mathrm{C}] /[\mathrm{H}]=1.0610^{-4}$ toward this star. This carbon abundance is a little lower than the average ratio seen in diffuse clouds (See Fig. 3 of their paper). So it is expected that the carbon-to-oxygen ratio in translucent clouds is lower than in diffuse clouds.
Table 1. The relative abundances of $\mathrm{C}$ and $\mathrm{O}$ and their ratio based on observation

\begin{tabular}{lllll}
\hline & Solar $^{1}$ & $\zeta \mathrm{Oph}^{2}$ & $\xi$ Per $^{2}$ & ${\text { Orion } \text { Bar }^{3}}^{2}$ \\
\hline $\mathrm{C}$ & $3.55 \mathrm{E}-4$ & $1.37 \mathrm{E}-4$ & $1.66 \mathrm{E}-4$ & $1.4 \mathrm{E}-4$ \\
$\mathrm{O}$ & $7.41 \mathrm{E}-4$ & $2.93 \mathrm{E}-4$ & $3.06 \mathrm{E}-4$ & $6.7 \mathrm{E}-4$ \\
{$[\mathrm{C}] /[\mathrm{O}]$} & 0.48 & 0.47 & 0.54 & 0.21 \\
\hline
\end{tabular}

${ }^{1}$ Savage \& Sembach (1996).

2 Cardelli et al. (1996).

${ }^{3}$ Walmsley et al. (1999).

In a recent study, Genaciński (2000) presented 10 new measurements of the carbon gas-phase abundance in the ISM. Unlike previous results, carbon depletion increases with the increase of the fractional molecular hydrogen abundance. For lines of sight with $\left[\mathrm{H}_{2}\right] /[\mathrm{H}]<10^{-3},[\mathrm{C}] /[\mathrm{H}]$ is $3.5510^{-4}$, which is close to the solar photospheric abundance, (Grevesse \& Noels 1993). For $\left[\mathrm{H}_{2}\right] /[\mathrm{H}]>10^{-3}$, $[\mathrm{C}] /[\mathrm{H}]$ is $1.3610^{-4}$. This result confirms the condensation of carbon from diffuse into molecular clouds. Poglitsch et al. (1996) derived a relative abundance of cold atomic oxygen of $[\mathrm{O}] /[\mathrm{H}] \geq 610^{-4}$ in the molecular cloud toward DR 21, expecting that most of the gas-phase oxygen in this cloud would be in atomic form. Although such single observations may not be generalized, it is useful in order to put some limits on the range of the initial oxygen abundances for such molecular clouds. Their result may support models that predict a high abundance of atomic oxygen in dark cores of molecular clouds. It may also answer the question of why all searches for molecular oxygen in the ISM have failed so far.

The recent observations of $\mathrm{C}$ and $\mathrm{O}$ are listed in Table 1 along with their ratios. The solar values are from Savage \& Sembach (1996), while data for $\zeta$ Oph, and $\xi$ Per are from Cardelli et al. (1996). Orion Bar data are from Walmsley et al. (1999). From Table 1 the $[\mathrm{C}] /[\mathrm{O}]$ ratio can vary in the range of $(0.21 \leq[\mathrm{C}] /[\mathrm{O}] \leq 0.54)$.

On the other hand, grain models tell us the required abundance of $\mathrm{C}$ and $\mathrm{O}$ in the interstellar dust. Grain models predict a certain depletion because the extinction must be produced by a distribution of solid particles. On average, the maximum available amount of silicates is inadequate to provide the total observed extinction.

Therefore, fractions of the more abundant organic species $(\mathrm{C}, \mathrm{N}, \mathrm{O}$ ) are required to exist in solid form (for an overview see van Dishoeck et al. 1993). As an example, a model in which the visual extinction is primarily provided by large $(\simeq 0.1 \mu \mathrm{m})$ core mantle particles and the ultraviolet extinction by small (carbonaceous) particles (or molecules), requires for the dust in low density (diffuse) clouds a carbon depletion of $\delta_{\mathrm{C}} \simeq 0.64$. About 0.34 of the depleted carbon is in the photoprocessed organic refractory coating of the silicates and about 0.25 in the small carbonaceous particles (Hong \& Greenberg 1980; Greenberg 1989). The model of Duley et al. (1989) has $\delta_{\mathrm{C}} \simeq 0.45$ in hydrogenated amorphous carbon coating 
Table 2. The relative abundances of $\mathrm{C}$ and $\mathrm{O}$ and its ratio based on interstellar grain models

\begin{tabular}{lllll}
\hline & Solar $^{1}$ & Core & Core + Icy mantle & Core + Hump + PAHs \\
\hline $\mathrm{C}$ & $3.55 \mathrm{E}-4$ & $2.47 \mathrm{E}-4$ & $2.40 \mathrm{E}-4$ & $1.61 \mathrm{E}-4$ \\
$\mathrm{O}$ & $7.41 \mathrm{E}-4$ & $6.37 \mathrm{E}-4$ & $5.40 \mathrm{E}-4$ & $6.37 \mathrm{E}-4$ \\
{$[\mathrm{C}] /[\mathrm{O}]$} & 0.48 & 0.4 & 0.44 & 0.25 \\
\hline
\end{tabular}

Based on Li \& Greenberg (1997).

${ }^{1}$ Savage \& Sembach (1996).

on the silicate grains and there must be additional carbon depletion for the ultra violet. The graphite-silicate model (Draine \& Lee 1984) has a total $\delta_{\mathrm{C}} \simeq 0.62$.

So in all cases carbon is depleted by $\delta_{\mathrm{C}}>0.5$ and the oxygen probably by $\delta_{\mathrm{O}} \leq 0.2$. Actually one might argue that in doing molecular cloud modeling one should include some initial depletion in the grain mantles for $\mathrm{H}_{2} \mathrm{O}, \mathrm{CO}_{2}$, and other most abundant species in the icy grain mantles. We have listed in Table 2 the carbon and oxygen abundances required by recent grain models (Li \& Greenberg 1997). For a reasonable gas-grain model, the $[\mathrm{C}] /[\mathrm{O}]$ ratio is in the range of $0.25 \leq[\mathrm{C}] /[\mathrm{O}] \leq 0.5$.

Combining the observational and the theoretical values from Tables 1 and 2, which in fact are close, we conclude that the $[\mathrm{C}] /[\mathrm{O}]$ ratio can vary from 0.5 for diffuse clouds to 0.20 for dense interstellar clouds.

\subsection{The sulfur depletion problem}

From observations and theoretical models of sulfurbearing molecules in dense clouds, it has been established that sulfur is roughly two orders of magnitude more depleted than are carbon, nitrogen, and oxygen (Ruffle et al. 1999). They suggested that much of the sulfur is in $\mathrm{S}^{+}$in translucent clumps with hydrogen number densities of less than $10^{3} \mathrm{~cm}^{-3}$ which play a significant role in determining why $\mathrm{S}$ is so depleted in denser regions. In these clumps the accretion rate of $\mathrm{S}^{+}$onto negatively charged grains is expected to be larger than onto neutral grains. Eventually in the collapse, gas-phase sulfur will be contained mostly in neutral species, which in Ruffle et al.'s picture leads to a large decrease in the sulfur depletion rate.

Kemper et al. (1999), in their best-fit model of the reflection nebulae CED 201, put constraints on the gasphase abundance of sulfur to be at 0.01 of its cosmic abundance. Federman et al. (1993) have shown that sulfur appears to have essentially a solar abundance $\left(1.6210^{-5}\right)$. This result is consistent with the finding of Savage (1992) for the depletion of volatile elements toward $\zeta$ Oph. However, their results for sulfur suggests depletion $(\mathrm{D}(\mathrm{S}) \geq-0.7)$ which means that the sulfur relative abundance is $3.2310^{-6}$. This is in agreement with the value of $310^{-6}$ that Ruffle et al. (1999) have derived.

For dense molecular clouds depletion of sulfur has been proposed by Caselli et al. (1994) to reproduce the observed abundances of solid CO.
Therefore, we conclude that the sulfur abundance can vary from values of $3.2310^{-6}$ for diffuse clouds down to $1.6210^{-7}$ for dense, dark molecular clouds. Although constraints on sulfur depletion are still uncertain and care should be taken in using any particular value, the range of the sulfur initial abundances used here is consistent with theoretical and observational results so far.

\subsection{The depletion of heavy elements}

Graedel et al. (1982) discussed this problem extensively. In their study three metal values (low, intermediate and high) were used. They concluded that using the assumed low metal abundance reproduces many aspects of dense chemistry (such as molecular ion abundances) more accurately. The tendency, since then, has been to lean toward the use of the so-called "Low-metal model" for many of the chemical models. This low metal set has been used by many authors dealing with gas-phase models (Herbst et al. 1986a,b, 1989; Millar \& Herbst 1990; Pineau Des Forêts et al. 1991). For gas-phase models Herbst \& Leung (1989) found that low metal abundances are necessary to form a sufficient amount of complex organic molecules, while Caselli et al. (1994) found that the use of the so-called "high-metal" elemental abundance in a gas-grain model leads to high abundances for solid CO, in better agreement with the observations. As a natural consequence of including gas-grain chemistry Shalabiea \& Greenberg (1994, 1995) returned to the earlier usage of the high metal abundances (Mitchell et al. 1978). They also concluded that high metal abundances are much more consistent with observation than low metal abundances as an initial ingredient of interstellar clouds.

Table 3. The relative abundances of heavy elements based on observations

\begin{tabular}{llllll}
\hline & Solar* & $\begin{array}{l}\zeta \text { Oph } \\
\text { gas }\end{array}$ & dust & $\begin{array}{l}\xi \text { Per } \\
\text { gas }\end{array}$ & dust \\
\hline $\mathrm{Mg}$ & $3.80 \mathrm{E}-5$ & $1.07 \mathrm{E}-6$ & $3.69 \mathrm{E}-5$ & $2.19 \mathrm{E}-6$ & $3.58 \mathrm{E}-5$ \\
$\mathrm{Si}$ & $3.55 \mathrm{E}-5$ & $1.74 \mathrm{E}-6$ & $3.38 \mathrm{E}-5$ & $1.95 \mathrm{E}-6$ & $1.60 \mathrm{E}-5$ \\
$\mathrm{Fe}$ & $3.24 \mathrm{E}-5$ & $1.74 \mathrm{E}-7$ & $3.22 \mathrm{E}-5$ & $2.63 \mathrm{E}-7$ & $3.21 \mathrm{E}-5$ \\
\hline
\end{tabular}

*Savage \& Sembach (1996). 
The observed abundances for heavy elements in the gas phase and their estimated values in dust are given in Table 3. The theoretical value for the heavy elements $\left(2.0410^{-5}\right)$ derived by $\mathrm{Li} \&$ Greenberg (1997) is indeed close to the observational values.

To sum up, the real depletion of the initial elements still has some uncertainties. However, based on recent observations from the Goddard High Resolution Spectrograph (GHRS) and theoretical grain models, they are well constrained within the following ranges: carbon: 3.55-1.4 $10^{-4}$, oxygen: $7.41-2.9410^{-4}$ with a ratio of $[\mathrm{C}] /[\mathrm{O}]$ from 0.21 to 0.54 , while for sulfur it can vary from its solar value $\left(1.6210^{-5}\right)$ to the depleted value $3.2310^{-6}$. For the heavy elements, the use of high metal abundances seems to meet both the observational and theoretical constraints.

Using the above mentioned constraints upon the initial elemental abundance, in the next sections we reconsider their effect and crucial role in chemical models in more detail for both gas-phase and gas-grain chemical models in this work.

\section{The chemical models and initial conditions}

Two chemical models have been used: one is a pure gasphase model while the second is characterized by combining grain interactions with the gas-phase chemistry. Accretion, surface reactions, and desorption processes are included in the gas-grain model. We have considered three possible desorption mechanisms: desorption as a result of $\mathrm{H}_{2}$ formation on grains, cosmic-ray-induced desorption and explosive desorption. It is possible that these processes can work at the same time even if one dominates the others under certain conditions. A detailed discussion of their importance and effectiveness is outside the scope of this work. It can be found in previous papers (e.g. Willacy \& Millar 1998). For the gas-phase set of reactions, we used the updated New Standard Model (NSM) reaction-rate values (Bettens et al. 1995).

The chemical evolution of interstellar clouds using these two models is investigated at specific values for the physical parameters. For dense interstellar clouds the following initial conditions have been used: total number density $n_{0}\left(n(\mathrm{H})+2 n\left(\mathrm{H}_{2}\right)\right)=210^{4} \mathrm{~cm}^{-3}, T_{\text {gas }}=$ $T_{\text {grain }}=10 \mathrm{~K}$, and visual extinction $A v=10 \mathrm{mag}$. The standard cosmic ray ionization rate $\zeta=1.310^{-17} \mathrm{~s}^{-1}$ has been used. The pseudo-time-dependent model evolves under these fixed physical conditions where the chemical abundances are allowed to evolve from the initial values until steady state is reached. The enhanced gas-grain network from the so-called unmodified model (Shalabiea et al. 1998) has been used based on the earlier models of Hasegawa \& Herbst (1993) and Hasegawa et al. (1992). It contains 656 species and 4742 reactions.

It should be noted that further studies are in progress on a new modified model as well as on the photochemistry on grain surfaces (Ruffle \& Herbst 2000, 2001). At the same time work by Caselli \& Herbst (in preparation)
Table 4. Adopted elemental abundances relative to total hydrogen for the standard model

\begin{tabular}{ll}
\hline Element & {$[\mathrm{X}] /[\mathrm{H}]$} \\
\hline $\mathrm{He}$ & $1.40 \mathrm{E}-1$ \\
$\mathrm{~N}$ & $7.94 \mathrm{E}-5$ \\
$\mathrm{O}$ & $3.02 \mathrm{E}-4$ \\
$\mathrm{C}^{+}$ & $1.38 \mathrm{E}-4$ \\
$\mathrm{~S}^{+}$ & $3.23 \mathrm{E}-6$ \\
$\mathrm{Si}^{+}$ & $1.74 \mathrm{E}-6$ \\
$\mathrm{Fe}^{+}$ & $1.74 \mathrm{E}-7$ \\
$\mathrm{Na}^{+}$ & $2.00 \mathrm{E}-7$ \\
$\mathrm{Mg}^{+}$ & $1.07 \mathrm{E}-6$ \\
\hline
\end{tabular}

Table 5. $[\mathrm{C}] /[\mathrm{O}]$ ratio and their initial abundances relative to total hydrogen

\begin{tabular}{lll}
\hline$[\mathrm{C}] /[\mathrm{O}]$ & $n_{\mathrm{C}} / n_{\mathrm{H}}$ & $n_{\mathrm{O}} / n_{\mathrm{H}}$ \\
\hline 0.2 & $6.01 \mathrm{E}-5$ & $3.02 \mathrm{E}-4$ \\
0.46 & $1.38 \mathrm{E}-4$ & $3.02 \mathrm{E}-4$ \\
0.8 & $2.45 \mathrm{E}-4$ & $3.02 \mathrm{E}-5$ \\
\hline
\end{tabular}

is being undertaken to provide appropriate modifications to surface reaction rates at temperatures above $10 \mathrm{~K}$. Therefore our next study will be on the sensitivity of initial elemental abundances to these most recent modified gas-grain models.

Based on our discussion in Sect. 2, we have listed the standard set of the adopted elemental abundances in Table 4 . We assumed that C, S, and other heavy elements are initially ionized and that most of hydrogen is in molecular form. The electron abundance is set equal to the sum of the ion abundances, so that the whole system is neutral. For metals we have used the so-called "high-metal" elemental abundances. Under this set of initial conditions, there is no bi-stable solution (see Shalabiea \& Greenberg 1995 and Lee et al. 1998).

\section{Results and discussion}

To examine the sensitivity of the models to varying the $[\mathrm{C}] /[\mathrm{O}]$ ratio, the results are given at three different ratios which are 0.2, 0.47 (standard) and 0.8. This ratio is varied between the lowest and highest values we may expect. The abundances of $\mathrm{C}$ and $\mathrm{O}$ and the $[\mathrm{C}] /[\mathrm{O}]$ ratios are listed in Table 5. Since the ages of the interstellar dense molecular clouds are not certain (van Dishoeck et al. 1993), we have presented the results at four points of time: $0.1,0.5$, 1 and $10 \mathrm{Myr}$. The results for some key species are shown in Figs. 1-6. In each figure, gas-phase models (a) are presented at the top and gas-grain models (b) at the bottom.

The results for two simple diatomic molecules $\mathrm{C}_{2}$ and $\mathrm{SO}$ are presented in Figs. 1 and 2, respectively. In Fig. 1a there is a clear difference between the low (0.2) and high (0.8) $[\mathrm{C}] /[\mathrm{O}]$ ratios. As expected the higher the carbon abundance, the more the $\mathrm{C}_{2}$ abundance. At early time $(0.1 \mathrm{Myr})$, the difference is only about one order of magnitude $\left(1.1510^{-9}\right.$ to $\left.3.010^{-8}\right)$. As time goes on the 

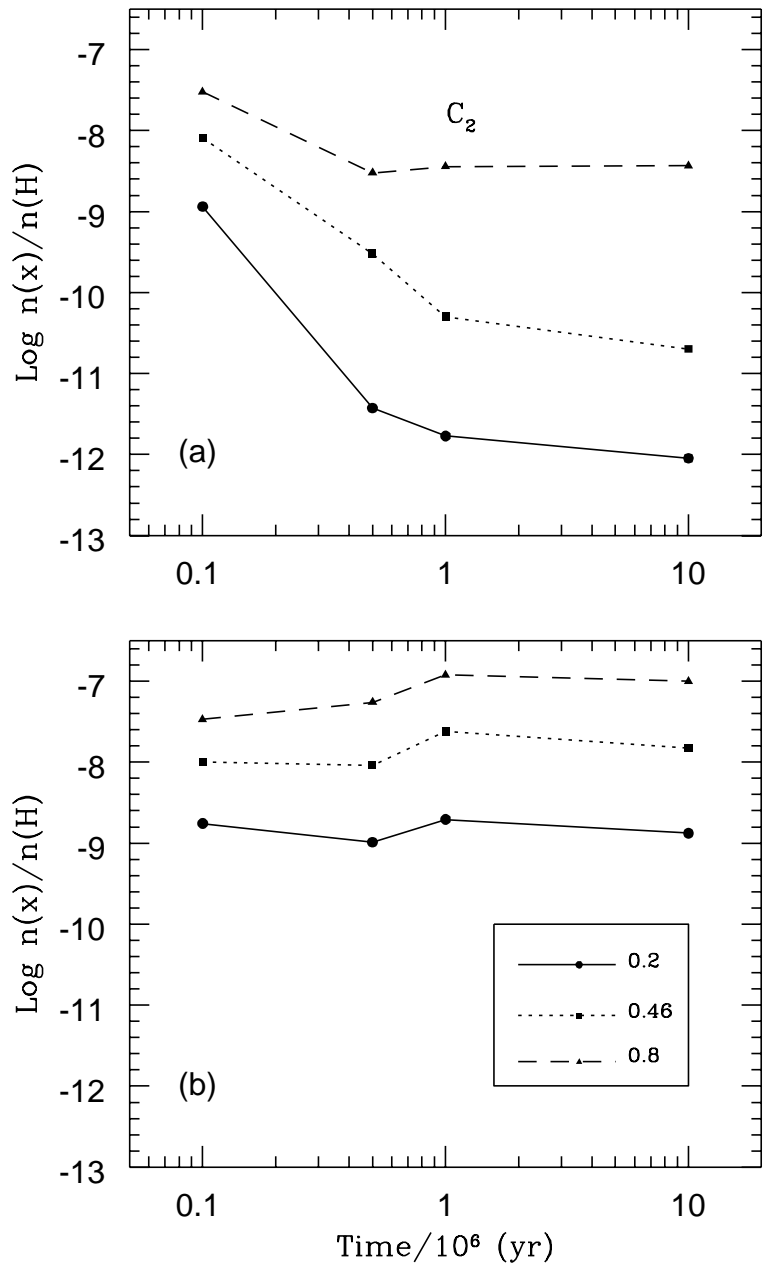

Fig. 1. Time evolution of the relative abundances of $\mathrm{C}_{2}$. For a) gas-phase and $\mathbf{b}$ ) gas-grain models for three values of the $[\mathrm{C}] /[\mathrm{O}]$ ratio (0.2 (solid line), 0.46 (long-dashed line) and 0.8 (dotted line))

difference increases to reach about four orders of magnitudes $\left(8.8910^{-13}-3.710^{-9}\right)$ at late time (10 Myr), which is indeed significant. In contrast, the results for gas-grain models, presented in Fig. 1b, show smaller differences (within two orders of magnitude) for $\mathrm{C}_{2}$. The abundance of $\mathrm{C}_{2}$ is steadier with time than that of the gas-phase model.

It is clear from Figs. 1 and 2 that even a small variation in the $[\mathrm{C}] /[\mathrm{O}]$ ratio can severely alter the abundances of $\mathrm{C}_{2}$ and $\mathrm{SO}$. The main routes of $\mathrm{C}_{2}$ formation in models (a) and (b), at early times are via,

$\mathrm{C}_{2} \mathrm{~N}^{+}+\mathrm{e} \longrightarrow \mathrm{C}_{2}+\mathrm{N} \quad 51 \%$
$\mathrm{C}_{2} \mathrm{H}_{2}^{+}+\mathrm{e} \longrightarrow \mathrm{C}_{2}+\mathrm{H}+\mathrm{H} \quad 17 \%$
$\mathrm{C}_{2} \mathrm{~S}^{+}+\mathrm{e} \longrightarrow \mathrm{C}_{2}+\mathrm{S} \quad 12 \%$
etc.

while its main destruction routes are via,

$\begin{array}{ll}\mathrm{C}_{2}+\mathrm{O} \longrightarrow \mathrm{CO}+\mathrm{C} & 77 \%(\mathrm{a}) \& 70 \%(\mathrm{~b}) \\ \mathrm{C}_{2}+\mathrm{N} \longrightarrow \mathrm{CN}+\mathrm{C} & 23 \%(\mathrm{a}) \& 30 \%(\mathrm{~b}) .\end{array}$

At early times, most of the parent (destroyer) molecules have similar or slightly different abundances in both gas-
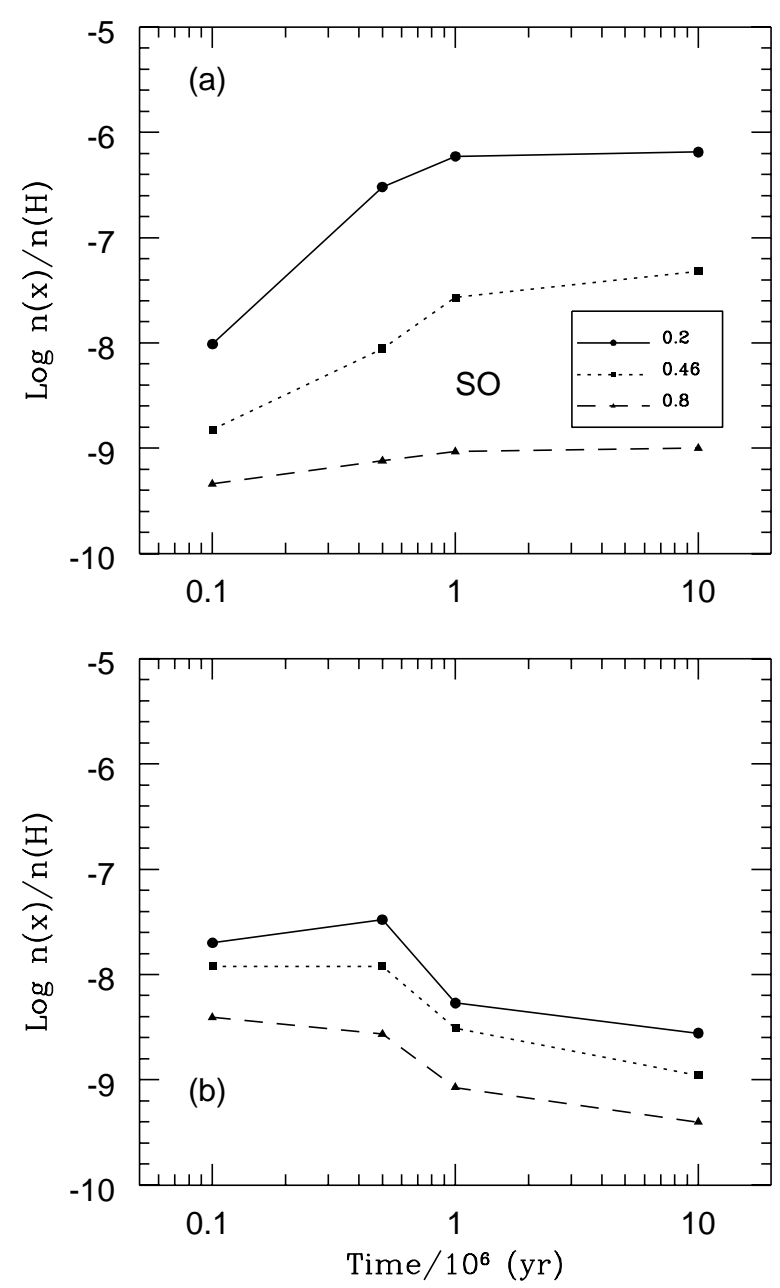

Fig. 2. Same as Fig. 1 but for SO

phase and gas grain models. For example at $0.1 \mathrm{Myr}$, O abundances are $2.610^{-4}$ and $1.610^{-4}$ for gas-phase and gas-grain models respectively, while its abundances at $10 \mathrm{Myr}$ are $1.810^{-4}$ and $2.010^{-6}$ for models (a) and (b), respectively. The same is true for other neutral species such as nitrogen whose abundances at $0.1 \mathrm{Myr}$ are $7.910^{-5}$ and $4.810^{-5}$ for models (a) and (b) respectively, while its abundances at $10 \mathrm{Myr}$ are $3.410^{-5}$ and $7.210^{-7}$ for models (a) and (b). This is about 2 orders higher in model (a) than in model (b).

Therefore the $\mathrm{C}_{2}$ abundances in the models (a) and (b) are comparable at early times. In contrast, at late times, model (b) has a higher $\mathrm{C}_{2}$ abundance than model (a) due to the lower abundances of its main destructive species $\mathrm{O}$ and $\mathrm{N}$. When we compare these results with observations for TMC-1, where the $\mathrm{C}_{2}$ abundance is $510^{-8}$, the best fit is for a $[\mathrm{C}] /[\mathrm{O}]$ ratio of 0.46 at time $1 \mathrm{Myr}$ for the gasgrain model. For the gas-phase model, at the same time and for the same $[\mathrm{C}] /[\mathrm{O}]$ ratio, the $\mathrm{C}_{2}$ is much lower than observed. Its abundance can only fit the observations for A high $[\mathrm{C}] /[\mathrm{O}]$ ratio of 0.8 .

The results for SO are shown in Fig. 2 for models (a) and (b) respectively. As for $\mathrm{C}_{2}$, the differences of the SO abundances in model (a) for $[\mathrm{C}] /[\mathrm{O}]$ ratio 0.2 and 0.8 respectively are large. For model (b) this difference in 

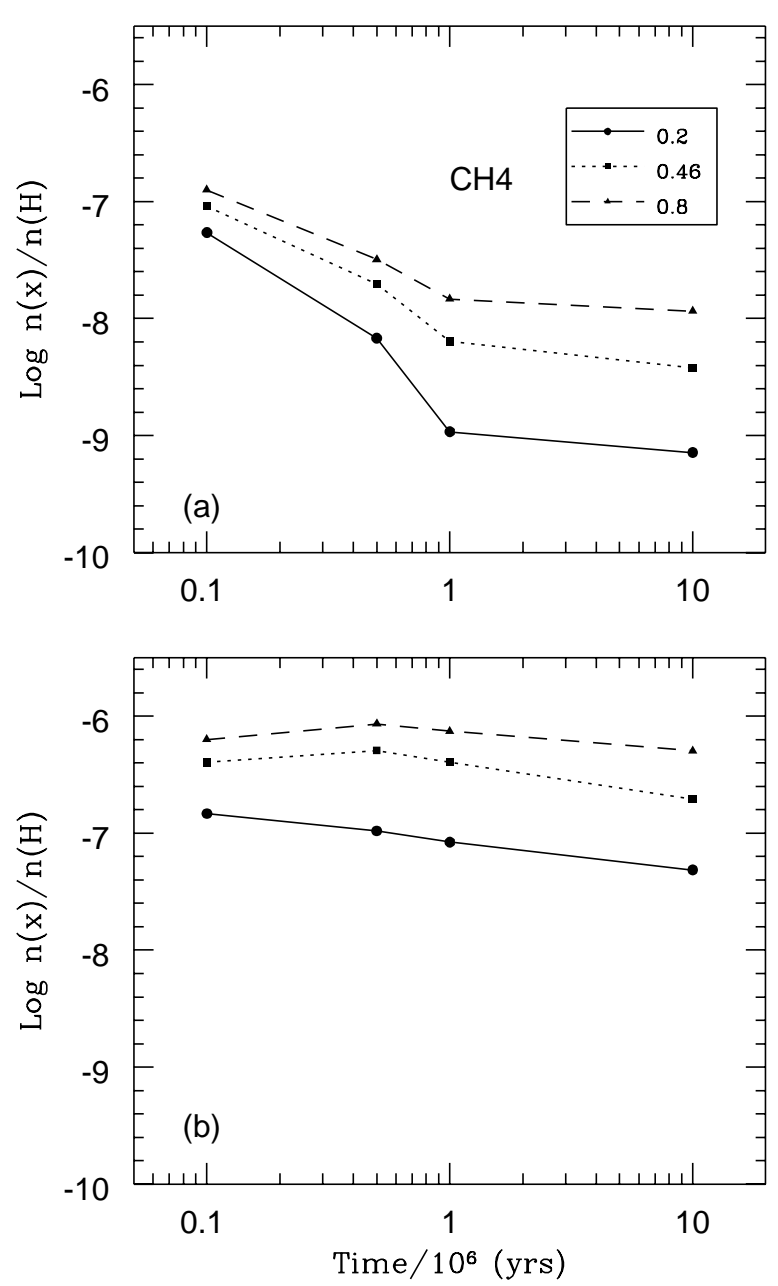

Fig. 3. Time evolution of the relative abundances of $\mathrm{CH}_{4}$. At the top gas-phase models a) results are presented. The results for gas-grain models $\mathbf{b}$ ) are shown at the bottom. The results are given given three values of $[\mathrm{C}] /[\mathrm{O}]$ ratio, 0.2 (solid line), 0.46 (long-dashed line) and 0.8 (dotted line)

SO abundance for low and high $[\mathrm{C}] /[\mathrm{O}]$ ratios is much smaller than in model (a); it is within an order of magnitude. The main routes of SO formation at early times are via,

$\mathrm{S}+\mathrm{O}_{2} \longrightarrow \mathrm{SO}+\mathrm{O}$

for

$\mathrm{HSO}^{+}+\mathrm{e} \longrightarrow \mathrm{SO}+\mathrm{H}$
$69 \%$ for models (a) and $46 \%$ models (b),

$25 \%$ for models (a) and $42 \%$ for models (b)

while its main destruction routes are;

$\begin{array}{ll}\mathrm{H}_{3}^{+}+\mathrm{SO} \longrightarrow \mathrm{HSO}^{+}+\mathrm{H}_{2} & 30 \% \\ \mathrm{C}^{+}+\mathrm{SO} \longrightarrow \mathrm{CO}^{+}+\mathrm{S} & 12 \% \\ \mathrm{C}^{+}+\mathrm{SO} \longrightarrow \mathrm{CS}^{+}+\mathrm{O} & 12 \% \\ \mathrm{C}^{+}+\mathrm{SO} \longrightarrow \mathrm{SO}^{+}+\mathrm{C} & 12 \% \\ \mathrm{C}^{+}+\mathrm{SO} \longrightarrow \mathrm{S}^{+}+\mathrm{CO} & 12 \% \\ \mathrm{H}^{+}+\mathrm{SO} \longrightarrow \mathrm{SO}^{+}+\mathrm{H} & 11 \% \\ \mathrm{O}+\mathrm{SO} \longrightarrow \mathrm{SO}_{2} \quad 9 \% . & \end{array}$

At early times, the SO abundance in model (b) is only two times higher than its abundance in model (a). This is
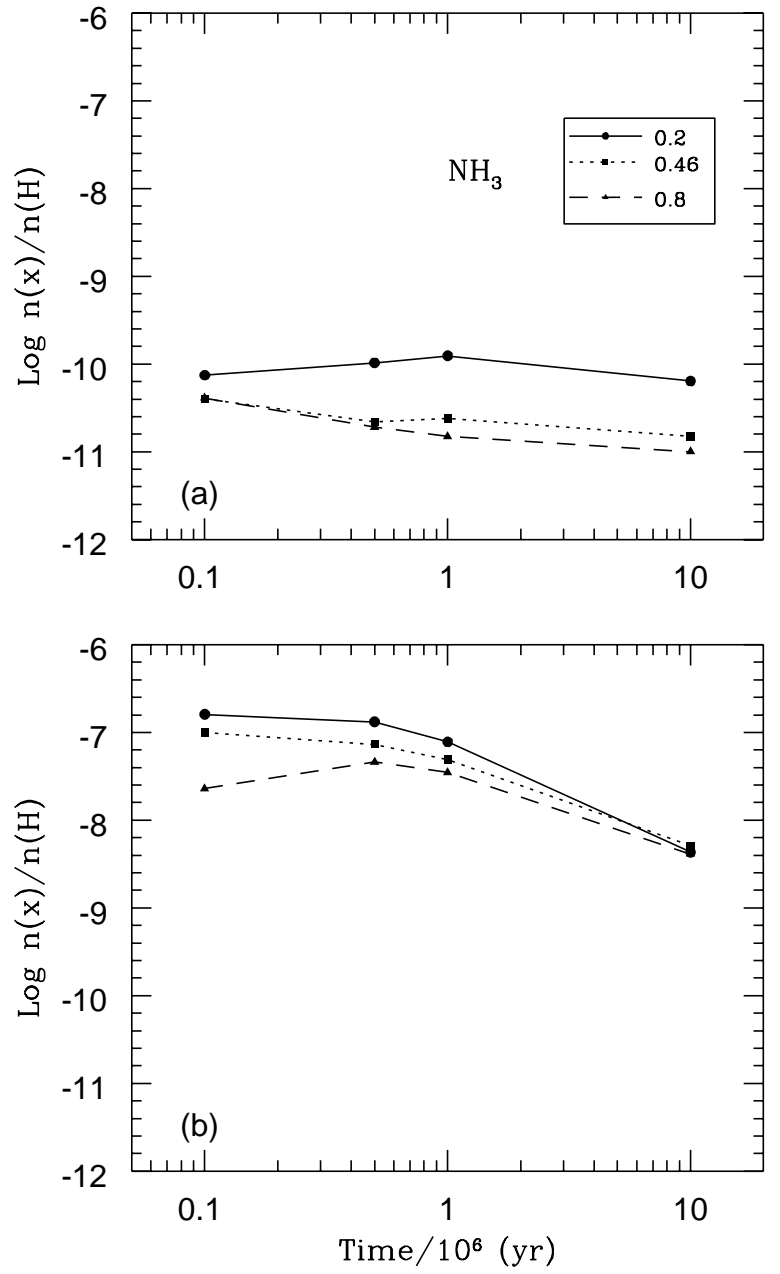

Fig. 4. The same as Fig. 3 but for $\mathrm{NH}_{3}$

mainly due to the high abundance of its precursor species $\mathrm{O}_{2}$ and the low abundance of its destructive species $\mathrm{C}^{+}$ in model (b). In contrast, at late times its abundance in model (a) is higher by about two orders of magnitude than in model (b). This is because the rate of its main production via the reactions of $\mathrm{HSO}^{+}+\mathrm{e}$ falls to only $2 \%$ instead of the $42 \%$ at early times in model(b). The reaction $\left(\mathrm{S}+\mathrm{O}_{2}\right)$ contributes $44 \%$ to its formation in model (a) at late times. This is due to the high gas-phase abundance of elemental $\mathrm{O}$ in model (a). In model (b) most of the oxygen is depleted on the grain surfaces in the form of $\mathrm{CO}$, $\mathrm{CO}_{2}$, and $\mathrm{H}_{2} \mathrm{O}$. Therefore, the $\mathrm{SO}$ abundance decreases with increasing time for model (b).

The observed abundances for SO in TMC-1 and L134N are $510^{-9}$ and $210^{-8}$ respectively. If we try to fit such observational values with the models, for TMC-1 we only obtain a good fit for model (b) in Fig. 2a, at $0.5 \mathrm{Myr}$ for $[\mathrm{C}] /[\mathrm{O}]=0.8$, while for $\mathrm{L} 134 \mathrm{~N}$ a $[\mathrm{C}] /[\mathrm{O}]$ of 0.46 gives good agreement at $1 \mathrm{Myr}$. The results shown for models (b) are in agreement with observed $\mathrm{SO}$ abundances in both TMC- 1 and $\mathrm{L} 134 \mathrm{~N}$ for $[\mathrm{C}] /[\mathrm{O}]=0.46$ at 1 and $0.5 \mathrm{Myr}$ respectively. For these simple diatomic molecules, we can conclude that gas-grain models are much less sensitive to $[\mathrm{C}] /[\mathrm{O}]$ variations than are gas-phase models. 
Table 6. Fractional abundances with respect to total $\mathrm{H}$ for two different ratios of $[\mathrm{C}] /[\mathrm{O}](0.2,0.8)$ at four different evolutionary times $(0.1,0.5,1,10 \mathrm{Myr})$ for the gas-phase chemical model

\begin{tabular}{|c|c|c|c|c|c|c|c|}
\hline & & \multicolumn{3}{|c|}{ Gas-phase model } & & \multicolumn{2}{|c|}{ Observations $^{a}$} \\
\hline & \multicolumn{7}{|l|}{$[\mathrm{C}] /[\mathrm{O}]$} \\
\hline \multirow[t]{2}{*}{$\mathrm{CO}$} & 0.2 & $3.837 \mathrm{E}-05$ & $6.086 \mathrm{E}-05$ & $6.090 \mathrm{E}-05$ & $6.090 \mathrm{E}-05$ & $1.6 \mathrm{E}-04$ & $1.8 \mathrm{E}-04$ \\
\hline & 0.8 & $1.195 \mathrm{E}-04$ & $2.231 \mathrm{E}-04$ & $2.324 \mathrm{E}-04$ & $2.337 \mathrm{E}-04$ & & \\
\hline \multirow[t]{2}{*}{$\mathrm{OH}$} & 0.2 & $1.389 \mathrm{E}-08$ & $1.906 \mathrm{E}-08$ & $2.100 \mathrm{E}-08$ & $2.237 \mathrm{E}-08$ & $6.0 \mathrm{E}-7$ & $1.6 \mathrm{E}-7$ \\
\hline & 0.8 & $6.020 \mathrm{E}-09$ & $5.896 \mathrm{E}-09$ & 5.970E-09 & $6.878 \mathrm{E}-09$ & & \\
\hline \multirow[t]{2}{*}{$\mathrm{CN}$} & 0.2 & $2.933 \mathrm{E}-08$ & $2.795 \mathrm{E}-10$ & $1.543 \mathrm{E}-10$ & $8.622 \mathrm{E}-11$ & $6.0 \mathrm{E}-08$ & $1.0 \mathrm{E}-09^{c}$ \\
\hline & 0.8 & $1.813 \mathrm{E}-07$ & $1.456 \mathrm{E}-07$ & $1.010 \mathrm{E}-07$ & $7.481 \mathrm{E}-08$ & & \\
\hline \multirow[t]{2}{*}{$\mathrm{NO}$} & 0.2 & $1.057 \mathrm{E}-08$ & $2.628 \mathrm{E}-08$ & $2.905 \mathrm{E}-08$ & $2.943 \mathrm{E}-08$ & $<6.0 \mathrm{E}-08$ & $1.2 \mathrm{E}-07$ \\
\hline & 0.8 & $1.760 \mathrm{E}-09$ & $5.829 \mathrm{E}-09$ & 7.513E-09 & $7.838 \mathrm{E}-09$ & & \\
\hline \multirow[t]{2}{*}{$\mathrm{C}_{2} \mathrm{H}$} & 0.2 & $5.899 \mathrm{E}-09$ & $3.325 \mathrm{E}-12$ & $4.519 \mathrm{E}-13$ & $2.999 \mathrm{E}-13$ & $1.0 \mathrm{E}-07$ & $1.0 \mathrm{E}-08^{c}$ \\
\hline & 0.8 & $1.668 \mathrm{E}-07$ & $2.148 \mathrm{E}-08$ & 8.543E-09 & 7.472E-09 & & \\
\hline \multirow[t]{2}{*}{$\mathrm{C}_{2} \mathrm{O}$} & 0.2 & $3.044 \mathrm{E}-13$ & $3.124 \mathrm{E}-15$ & $4.231 \mathrm{E}-16$ & $2.671 \mathrm{E}-16$ & $1.2 \mathrm{E}-10^{b}$ & .. \\
\hline & 0.8 & $3.368 \mathrm{E}-12$ & $4.934 \mathrm{E}-13$ & $2.485 \mathrm{E}-13$ & $2.290 \mathrm{E}-13$ & & \\
\hline \multirow[t]{2}{*}{$\mathrm{HCN}$} & 0.2 & $2.563 \mathrm{E}-08$ & $4.650 \mathrm{E}-10$ & $3.107 \mathrm{E}-10$ & $1.465 \mathrm{E}-10$ & $4.0 \mathrm{E}-08$ & $1.4 \mathrm{E}-08^{c}$ \\
\hline & 0.8 & $7.418 \mathrm{E}-08$ & $1.601 \mathrm{E}-08$ & 7.684E-09 & $4.956 \mathrm{E}-09$ & & \\
\hline \multirow[t]{2}{*}{$\mathrm{C}_{2} \mathrm{~S}$} & 0.2 & $7.803 \mathrm{E}-10$ & $2.143 \mathrm{E}-11$ & $1.687 \mathrm{E}-12$ & $8.803 \mathrm{E}-13$ & $1.6 \mathrm{E}-08$ & $1.2 \mathrm{E}-09$ \\
\hline & 0.8 & $1.228 \mathrm{E}-09$ & $4.690 \mathrm{E}-10$ & $3.807 \mathrm{E}-10$ & $9.456 \mathrm{E}-09$ & & \\
\hline \multirow[t]{2}{*}{$\mathrm{H}_{2} \mathrm{~S}$} & 0.2 & $1.606 \mathrm{E}-11$ & $1.301 \mathrm{E}-11$ & $1.102 \mathrm{E}-11$ & $3.460 \mathrm{E}-12$ & $<1.0 \mathrm{E}-09$ & $1.6 \mathrm{E}-09$ \\
\hline & 0.8 & $7.917 \mathrm{E}-12$ & $5.774 \mathrm{E}-12$ & $5.309 \mathrm{E}-12$ & $2.567 \mathrm{E}-12$ & & \\
\hline \multirow[t]{2}{*}{ OCS } & 0.2 & $8.088 \mathrm{E}-09$ & $4.941 \mathrm{E}-09$ & $5.121 \mathrm{E}-09$ & 4.943E-09 & 4.0E-09 & 4.0E-09 \\
\hline & 0.8 & $1.488 \mathrm{E}-08$ & $5.768 \mathrm{E}-09$ & $4.168 \mathrm{E}-09$ & 3.929E-09 & & \\
\hline \multirow{2}{*}{$\mathrm{SO}_{2}$} & 0.2 & $1.872 \mathrm{E}-09$ & $1.178 \mathrm{E}-07$ & $2.732 \mathrm{E}-07$ & $3.150 \mathrm{E}-07$ & $<2.0 \mathrm{E}-09$ & $6.0 \mathrm{E}-09^{c}$ \\
\hline & 0.8 & $3.873 \mathrm{E}-11$ & $3.183 \mathrm{E}-11$ & $3.548 \mathrm{E}-11$ & $3.906 \mathrm{E}-11$ & & \\
\hline \multirow[t]{2}{*}{$\mathrm{HC}_{3} \mathrm{~N}$} & 0.2 & $1.081 \mathrm{E}-12$ & $1.081 \mathrm{E}-12$ & $7.027 \mathrm{E}-14$ & $1.993 \mathrm{E}-14$ & $1.2 \mathrm{E}-07^{b}$ & $8.0 \mathrm{E}-10^{c}$ \\
\hline & 0.8 & $1.932 \mathrm{E}-08$ & $2.004 \mathrm{E}-09$ & $6.531 \mathrm{E}-10$ & $4.274 \mathrm{E}-10$ & & \\
\hline \multirow[t]{2}{*}{$\mathrm{C}_{4} \mathrm{H}$} & 0.2 & $1.416 \mathrm{E}-10$ & $1.655 \mathrm{E}-13$ & $1.191 \mathrm{E}-14$ & $6.846 \mathrm{E}-15$ & $8.0 \mathrm{E}-07^{c}$ & 2.0E-09 \\
\hline & 0.8 & $1.873 \mathrm{E}-08$ & $4.758 \mathrm{E}-10$ & $1.057 \mathrm{E}-10$ & $7.486 \mathrm{E}-11$ & & \\
\hline \multirow[t]{2}{*}{$\mathrm{C}_{6} \mathrm{H}$} & 0.2 & $1.126 \mathrm{E}-14$ & $1.707 \mathrm{E}-17$ & 8.319E-19 & $1.030 \mathrm{E}-22$ & $4.0 \mathrm{E}-10^{b}$ & .. \\
\hline & 0.8 & $2.293 \mathrm{E}-11$ & $1.302 \mathrm{E}-13$ & $8.096 \mathrm{E}-15$ & $8.096 \mathrm{E}-15$ & & \\
\hline \multirow[t]{2}{*}{$\mathrm{C}_{3} \mathrm{H}_{2}$} & 0.2 & $1.971 \mathrm{E}-10$ & $2.285 \mathrm{E}-13$ & $1.602 \mathrm{E}-14$ & $9.797 \mathrm{E}-15$ & $8.0 \mathrm{E}-09^{b}$ & 4.0E-09 \\
\hline & 0.8 & $1.061 \mathrm{E}-08$ & $7.686 \mathrm{E}-10$ & $2.343 \mathrm{E}-10$ & $1.855 \mathrm{E}-10$ & & \\
\hline \multirow[t]{2}{*}{$\mathrm{CH}_{2} \mathrm{CO}$} & 0.2 & $3.976 \mathrm{E}-11$ & $1.576 \mathrm{E}-12$ & $9.633 \mathrm{E}-13$ & $7.784 \mathrm{E}-13$ & $1.2 \mathrm{E}-09^{b}$ & $<1.4 \mathrm{E}-09$ \\
\hline & 0.8 & $2.096 \mathrm{E}-10$ & $5.854 \mathrm{E}-11$ & $3.315 \mathrm{E}-11$ & $2.642 \mathrm{E}-11$ & & \\
\hline \multirow[t]{2}{*}{$\mathrm{HCO}^{+}$} & 0.2 & $9.398 \mathrm{E}-11$ & $1.638 \mathrm{E}-10$ & $1.825 \mathrm{E}-10$ & $1.769 \mathrm{E}-10$ & $1.6 \mathrm{E}-08$ & $1.6 \mathrm{E}-08$ \\
\hline & 0.8 & $1.575 \mathrm{E}-10$ & $2.090 \mathrm{E}-10$ & $2.007 \mathrm{E}-10$ & $1.906 \mathrm{E}-10$ & & \\
\hline \multirow[t]{2}{*}{$\mathrm{N}_{2} \mathrm{H}^{+}$} & 0.2 & $2.008 \mathrm{E}-13$ & $2.506 \mathrm{E}-12$ & $6.409 \mathrm{E}-12$ & $2.268 \mathrm{E}-11$ & $1.0 \mathrm{E}-09$ & $1.2 \mathrm{E}-09^{c}$ \\
\hline & 0.8 & $2.969 \mathrm{E}-14$ & $2.029 \mathrm{E}-13$ & $5.037 \mathrm{E}-13$ & $3.442 \mathrm{E}-12$ & & \\
\hline \multirow[t]{2}{*}{$\mathrm{HCS}^{+}$} & 0.2 & $2.584 \mathrm{E}-11$ & $7.956 \mathrm{E}-12$ & $1.224 \mathrm{E}-11$ & $1.258 \mathrm{E}-11$ & $6.0 \mathrm{E}-10^{b}$ & $1.2 \mathrm{E}-10$ \\
\hline & 0.8 & $1.228 \mathrm{E}-10$ & $9.114 \mathrm{E}-11$ & $6.545 \mathrm{E}-11$ & $7.468 \mathrm{E}-11$ & & \\
\hline
\end{tabular}

\footnotetext{
${ }^{a}$ Ohishi et al. (1992) unless otherwise noted.

${ }^{b}$ Ohishi et al. (1998).

${ }^{c}$ Dickens et al. (2000).
}

To examine the effect of $[\mathrm{C}] /[\mathrm{O}]$ variations on slightly more complex species, we present results for $\mathrm{CH}_{4}$ and $\mathrm{NH}_{3}$ in Figs. 3 and 4 respectively. Figure 3a shows that $\mathrm{CH}_{4}$ follows the trend of a high abundance for carbonaceous species when $[\mathrm{C}] /[\mathrm{O}]$ is as high as 0.8 in both gasphase and gas-grain. For gas-phase models, the difference is about an order of magnitude between the 0.2 and 0.8 ratios. The same behavior can be found for the gas-grain models in Fig. 3b. Note that in gas-phase models these differences increase with time. We also found that the abundance of $\mathrm{CH}_{4}$ decreased sharply with time. This is not the case for gas-grain models, where the $\mathrm{CH}_{4}$ abundance remains high and fairly stable, showing only a slight decrease with time. Unlike the diatomic molecules, the main routes for $\mathrm{CH}_{4}$ in model (a) are different from model (b).

For model (a), at early times, the main formation routes are

\begin{tabular}{l}
$\mathrm{CH}_{5}^{+}+\mathrm{e} \longrightarrow \mathrm{CH}_{4}+\mathrm{H}$ \\
$\mathrm{CH}_{5}^{+}+\mathrm{CO} \longrightarrow \mathrm{HCO}^{+}+\mathrm{CH}_{4} \quad 95 \%$ \\
\hline
\end{tabular}

while its main destruction routes are via its reaction with photons induced by cosmic rays and reactions with $\mathrm{C}^{+}$, $\mathrm{S}^{+}, \mathrm{H}^{+}$and $\mathrm{He}^{+}$. For model (b) its production is mainly 
Table 7. Fractional abundances with respect to total $\mathrm{H}$ for two different ratios of $[\mathrm{C}] /[\mathrm{O}](0.2$ and 0.8$)$ at four $(0.1,0.5,1.0$ and $10 \mathrm{Myr}$ ) different evolutionary times for gas-grain model

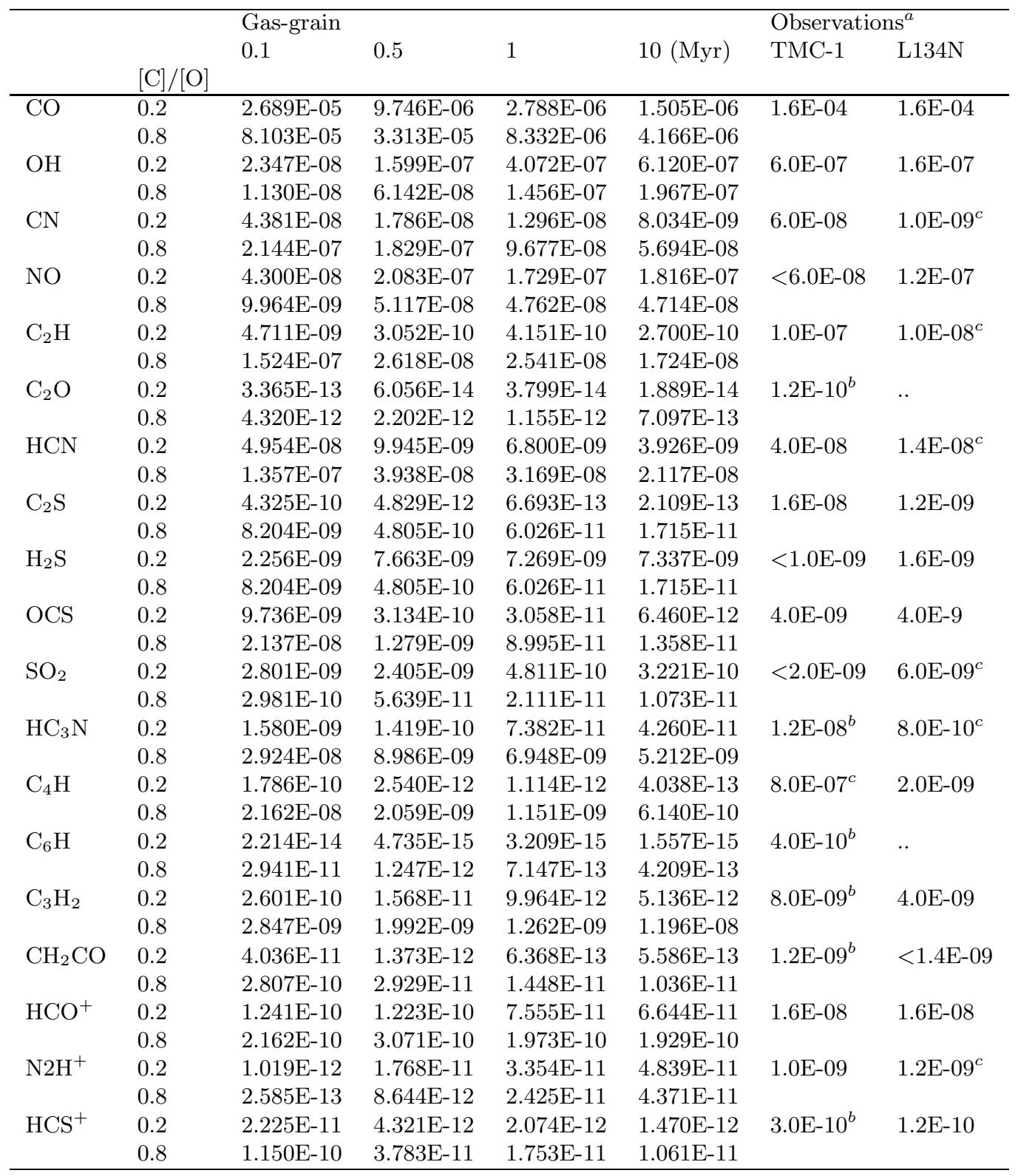

${ }^{a}$ Ohishi et al. (1992) unless otherwise noted.

${ }^{b}$ Ohishi et al. (1998).

${ }^{c}$ Dickens et al. (2000).

by desorption of solid $\mathrm{CH}_{4}$ from the grain surface. Its destruction routes are via its accretion onto grain surfaces, and its reaction with photons induced by cosmic ray and by ion species $\left(\mathrm{H}_{3}^{+}, \mathrm{C}^{+}, \mathrm{S}^{+}, \mathrm{H}^{+}\right.$, and $\left.\mathrm{He}^{+}\right)$. Despite these different routes of formation and destruction, the difference between $\mathrm{CH}_{4}$ abundance in model (a) and (b) is not large. It is only 3 times higher in model (b) than in model (a). This is mainly due to the decrease of the abundance of its main parent ion $\left(\mathrm{CH}_{5}^{+}\right)$by about 2 orders of magnitude in model (a). In model (b) its formation on grain surfaces and desorption to the gas-phase keeps its abundance high, although it decreases slightly with time. Therefore, its abundance in model (b) is about 80 times higher than in model (a) at late times.

Figure 4 shows that $\mathrm{NH}_{3}$ follows the same trend as $\mathrm{CH}_{4}$ but the effect due to the $[\mathrm{C}] /[\mathrm{O}]$ variation is very small for both of the models (a) and (b). However the results for models (b) are higher than those for models (a) by orders of magnitudes. The main formation route for $\mathrm{NH}_{3}$ is via $\mathrm{NH}_{4}^{+}+\mathrm{e} \longrightarrow \mathrm{NH}_{3}+\mathrm{H} \quad 100 \%$.

Its destruction routes are via its reaction with the $\mathrm{Si}^{+}, \mathrm{S}^{+}$, 

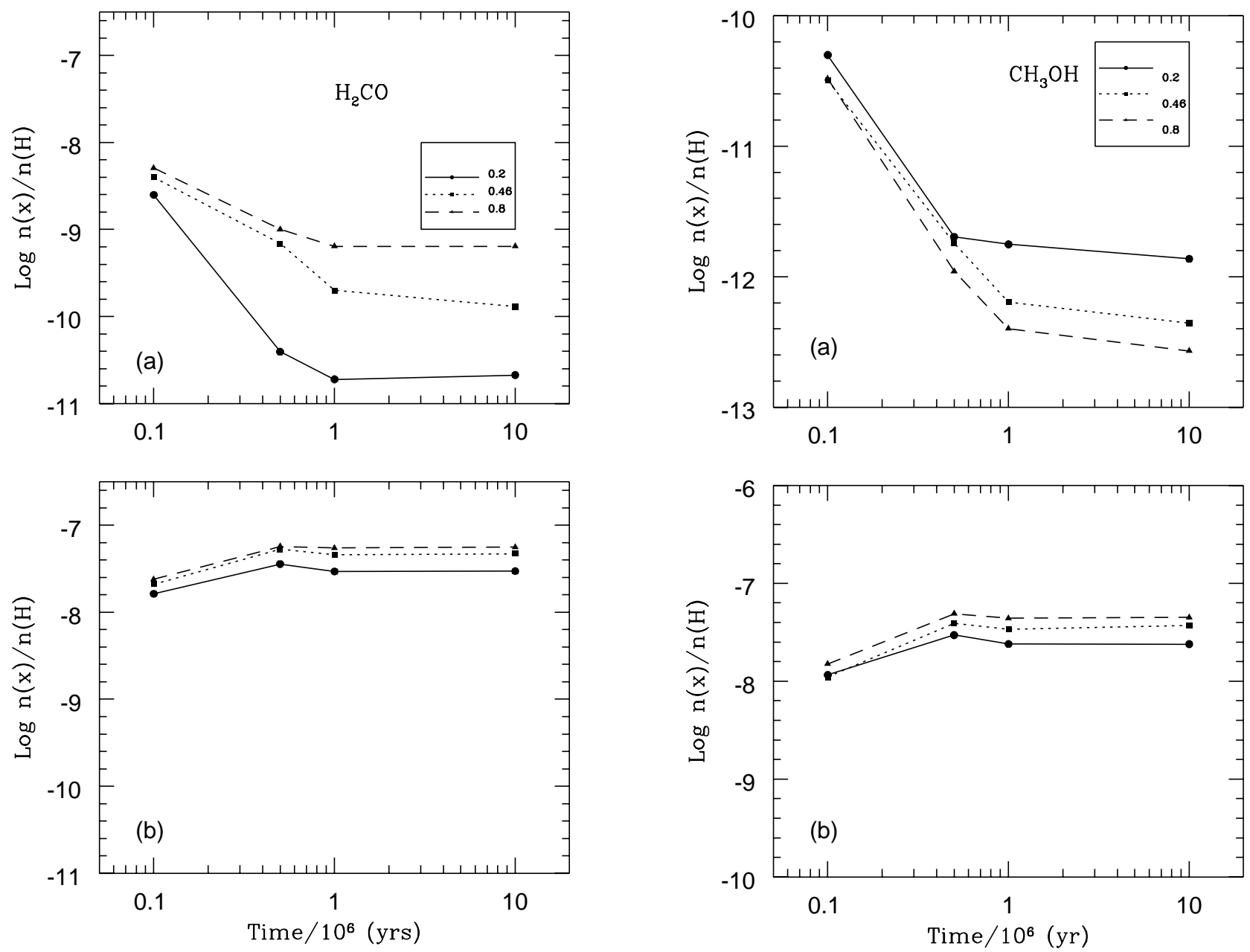

Fig. 5. Time evolution of the relative abundances of $\mathrm{H}_{2} \mathrm{CO}$. At the top gas-phase models a) are presented while the gas-grain models b) are at the bottom. The results are given for three values of $[\mathrm{C}] /[\mathrm{O}]$ ratio, 0.2 (solid line), 0.46 (long-dashed line) and 0.8 (dotted line)

$\mathrm{H}_{3}^{+}, \mathrm{C}^{+}, \mathrm{H}^{+}$and $\mathrm{He}^{+}$ions, and neutral-neutral reactions with $\mathrm{CN}$.

In model (b), like $\mathrm{CH}_{4}$, ammonia is formed mainly on grain surfaces, then desorbed to the gas phase, while its destruction routes are via its accretion onto grain surfaces, and reactions with ion species $\left(\mathrm{H}_{3}^{+}, \mathrm{He}^{+}, \mathrm{Si}^{+}, \mathrm{H}^{+}\right)$ and neutral-neutral reaction with $\mathrm{CN}$. From these routes of $\mathrm{NH}_{3}$ formation and destruction, it is obvious that the value of $[\mathrm{C}] /[\mathrm{O}]$ has very little effect on the abundance of $\mathrm{NH}_{3}$, mainly because neither carbon, nor oxygen, nor their bearing molecular species are involved in its formation or destruction.

In a comparison with the observations, we find that the results of models (b) are in agreement with the TMC1 abundance $\left(10^{-8}\right)$ at about $5 \mathrm{Myr}$, but for L134N, where the fractional abundance of ammonia is $210^{-7}$, the best agreement requires an early time of $0.5 \mathrm{Myr}$ and $[\mathrm{C}] /[\mathrm{O}]=$ 0.46. If this is the case then $\mathrm{NH}_{3}$ could be a good indicator for the age of these molecular clouds.

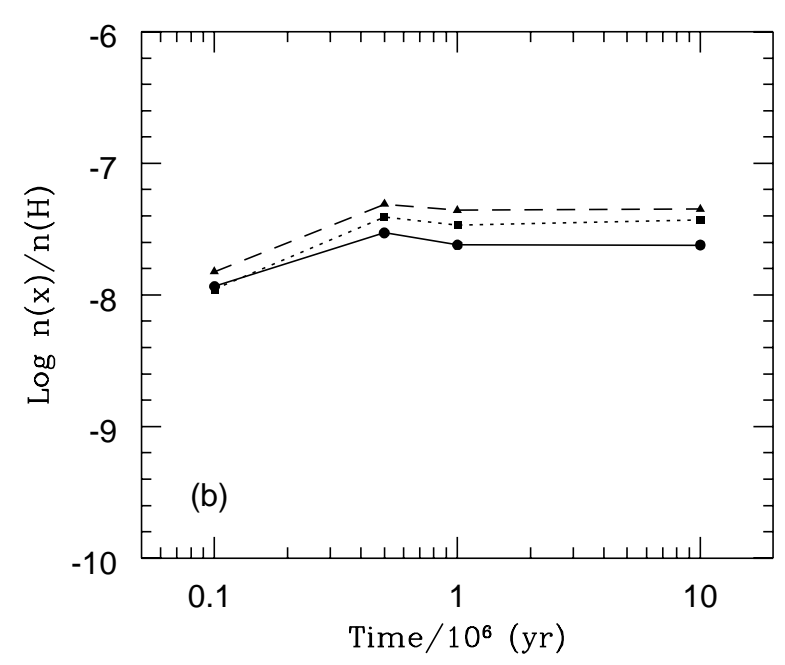

Fig. 6. The same as Fig. 5 but for $\mathrm{CH}_{3} \mathrm{OH}$

The results for more complex species such as $\mathrm{H}_{2} \mathrm{CO}$ and $\mathrm{CH}_{3} \mathrm{OH}$ are shown in Figs. 5 and 6 respectively. The $\mathrm{H}_{2} \mathrm{CO}$ molecule is a good example for showing the importance of what set of elemental abundances is adopted. For model (a), the difference between the results for $[\mathrm{C}] /[\mathrm{O}]=$ 0.2 or 0.8 is two orders of magnitude at late times, while at early times its abundance is almost the same. Since at early times most of the $\mathrm{H}_{2} \mathrm{CO}$ parent species have similar abundances, there is a small difference between the different ratios of $[\mathrm{C}] /[\mathrm{O}]$. Its main formation routes at early times are as follows
$\mathrm{O}+\mathrm{CH}_{3} \longrightarrow \mathrm{H}_{2} \mathrm{CO}+\mathrm{H}$
$62 \%$
$\mathrm{CH}_{2} \mathrm{Si}^{+}+\mathrm{O} \longrightarrow \mathrm{Si}+\mathrm{H}_{2} \mathrm{CO}$
$33 \%$
$\mathrm{H}_{3} \mathrm{CO}^{+}+\mathrm{e} \longrightarrow \mathrm{H}_{2} \mathrm{CO}+\mathrm{H}$
$5 \%$.

It is destroyed by its reactions with ionic species $\left(\mathrm{S}^{+}, \mathrm{H}_{3}^{+}\right.$, and $\mathrm{C}^{+}$). At late times its formation routes are the same as at early times with somewhat different ratios. It is also destroyed by its reaction with the ionic species $\mathrm{S}^{+}, \mathrm{H}_{3}^{+}$, $\mathrm{C}^{+}$and $\mathrm{H}^{+}$and by photon-induced cosmic ray destruction. The abundances of $\mathrm{O}$ and $\mathrm{CH}_{3}$ become two and 100 times, respectively, lower than their early-time values; this leads to the severe underproduction of $\mathrm{H}_{2} \mathrm{CO}$ at the medium and late times for models (a). When $[\mathrm{C}] /[\mathrm{O}]$ becomes high, a natural consequence is that the $\mathrm{H}_{2} \mathrm{CO}$ 

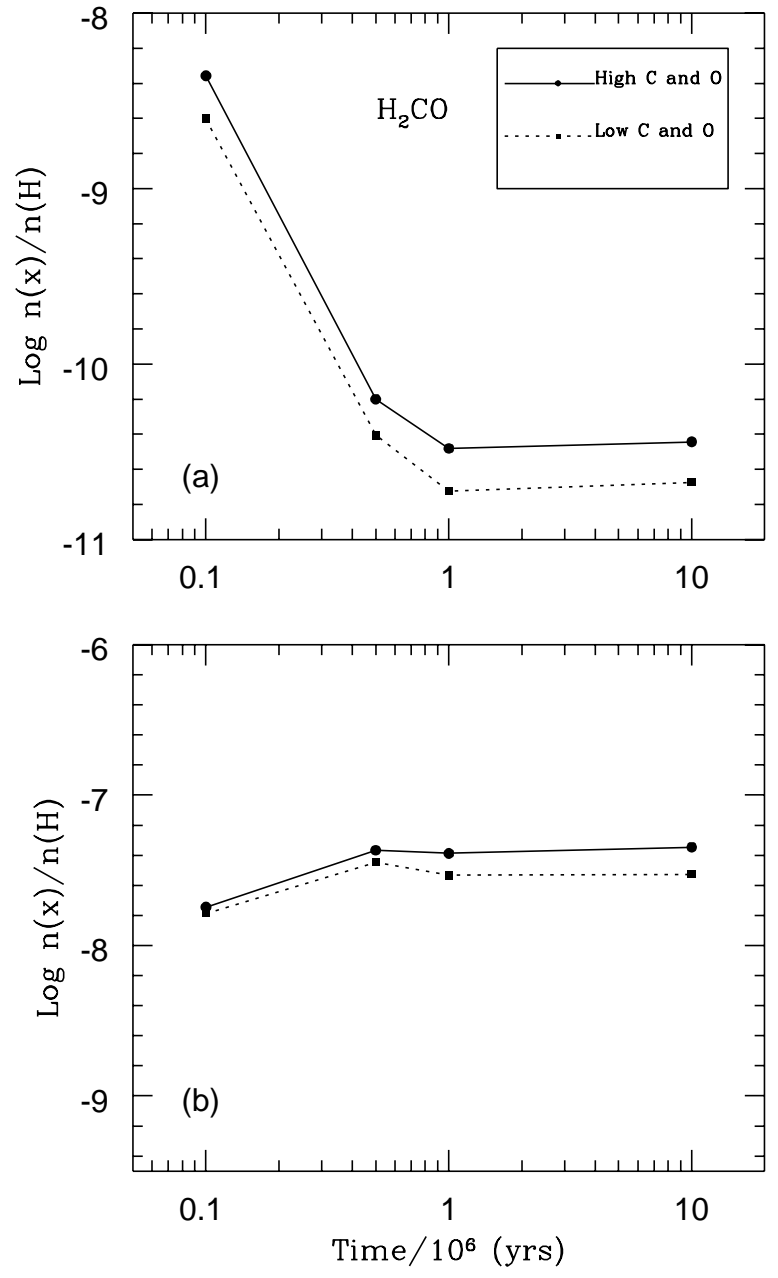

Fig. 7. Evolution of the relative abundances of $\mathrm{H}_{2} \mathrm{CO}$ in the gas-phase a) for set 1 of high $\mathrm{C}$ and $\mathrm{O}$ (solid line), and for set 2 of low $\mathrm{C}$ and $\mathrm{O}$ (dashed line). In both sets the $[\mathrm{C}] /[\mathrm{O}]$ ratio was fixed to 0.2 . b) The same as a) but for gas-grain models

abundance increases. Thus the difference between the low and the high $[\mathrm{C}] /[\mathrm{O}]$ ratio at late times becomes around two orders of magnitude, as shown in Fig. 5a.

Unlike the (a) model, the gas-grain model (b) shows little sensitivity to the variations of the $[\mathrm{C}] /[\mathrm{O}]$ ratio in Fig. 5b. The differences between the results of the three $[\mathrm{C}] /[\mathrm{O}]$ ratios are almost negligible. For model (b), the main formation routes are due to its desorption from the grain surface, while it is mainly destroyed at early times via its reaction with the $\mathrm{H}_{3}^{+}, \mathrm{S}^{+}, \mathrm{C}^{+}$and $\mathrm{He}^{+}$ions. It is mainly destroyed at late times only by its reaction with $\mathrm{H}_{3}^{+}$and $\mathrm{He}^{+}$. The latter two ions already have low abundances at late times. In a comparison with the observations, the results for models (b) seem a bit higher than those of TMC-1 and L134N $\left(210^{-8}\right)$. On the other hand, the results of $\mathrm{H}_{2} \mathrm{CO}$ in models (a) are low by three orders of magnitude for $[\mathrm{C}] /[\mathrm{O}]=0.2$. Even for $[\mathrm{C}] /[\mathrm{O}]=(0.8)$ they are still ten times lower than the observed value.

The observed abundances of $\mathrm{CH}_{3} \mathrm{OH}$ for TMC-1 $\left(310^{-9}\right)$ and $\operatorname{L134N}\left(510^{-9}\right)$ are higher than the values of model (a) in Fig. 6a, by more than 4 orders of magni-
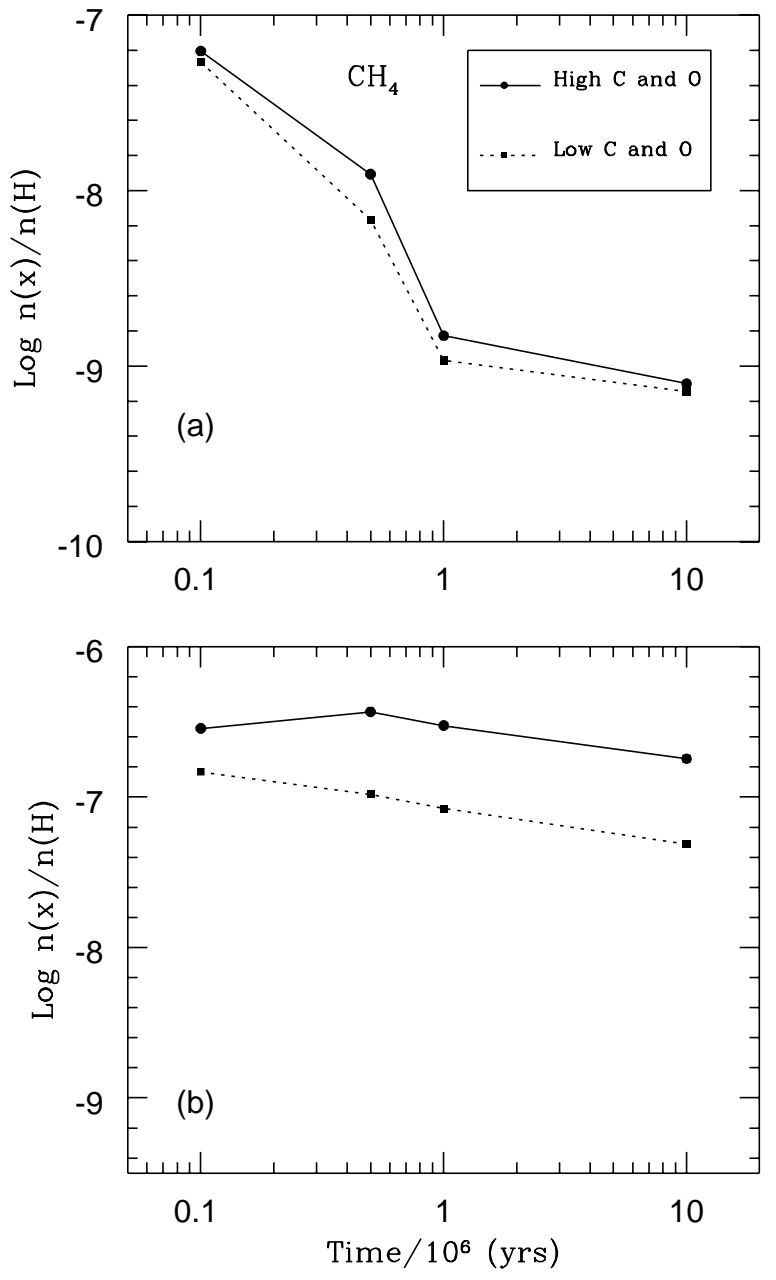

Fig. 8. Same as Fig. 7 but for $\mathrm{CH}_{4}$

tude. For model (a), the difference between the $\mathrm{CH}_{3} \mathrm{OH}$ results for the high $[\mathrm{C}] /[\mathrm{O}]$ value $(0.8)$ and the low one $(0.2)$ reaches an order of magnitude at late times. This difference is almost negligible at early times $\left(\leq 10^{5} \mathrm{Myr}\right)$. Its main formation route in models (a) is via,

$\mathrm{CH}_{5} \mathrm{O}^{+}+\mathrm{e} \longrightarrow \mathrm{CH}_{4} \mathrm{O}+\mathrm{H} \quad 100 \%$,

while its destruction comes via reactions with $\mathrm{H}_{3}^{+}, \mathrm{H}^{+}$, $\mathrm{He}^{+}$, and photon induced by cosmic rays.

In the gas-grain model (b) the abundances are higher than the observed values by one order of magnitude. This could be due to either A high formation rate on the grain surfaces and/or efficiency of desorption. Its main route of formation is, as for $\mathrm{H}_{2} \mathrm{CO}$, via its desorption from the grain surface. In a similar manner for complex molecules, $\mathrm{CH}_{3} \mathrm{OH}$ is destroyed via its reactions with $\mathrm{H}_{3}^{+}$and $\mathrm{He}^{+}$.

From these two examples of complex molecules, we still see a crucial role for the variation of the $[\mathrm{C}] /[\mathrm{O}]$ elemental abundance in model (a). Model (b), on the other hand, is relatively insensitive to the variations of the $[\mathrm{C}] /[\mathrm{O}]$ ratio. These variations are almost negligible for gas-grain models if the $[\mathrm{C}] /[\mathrm{O}]$ ratio varies only from 0.4 to 0.5 as suggested by Pratap et al. (1997) or from 0.4 to 0.8 by Bergin et al. (1997) in studies with gas-phase models. The results for more gas-phase species are listed in Tables 6 and 7 for 

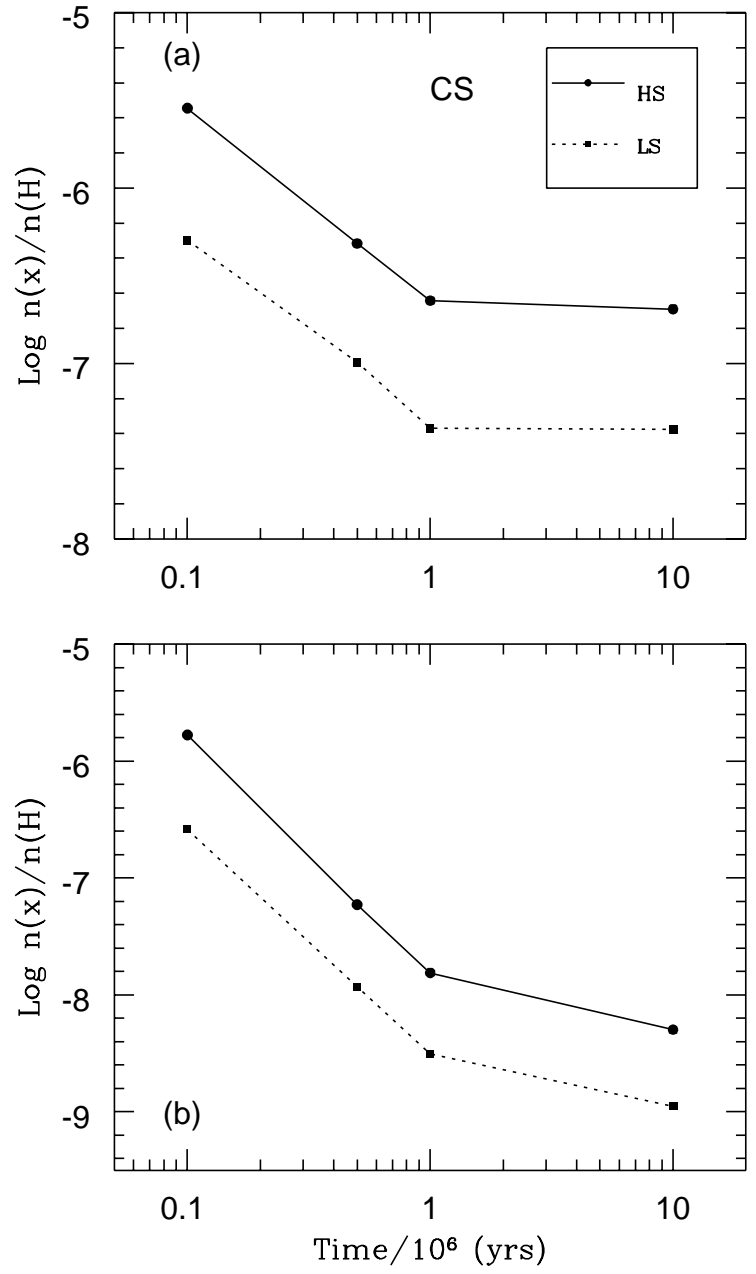

Fig. 9. The effects of high and low sulfur elemental abundances. Evolution of the relative abundances of CS in the gasphase a) for high sulfur (HS) $\left(1.6210^{-5}\right)$ (solid line), and low sulfur (LS) $\left(3.2310^{-6}\right)$. b) The same as a) but for gas-grain models

gas-phase and gas-grain models respectively. Although it is not our main goal to fit our results for any particular object, the observed abundances in TMC-1 and L134N are presented for comparison. It is useful in understanding at which ratio and at what time, results are in agreement with observations for the gas-phase and gas-grain model. We listed the results at the two extreme values of $[\mathrm{C}] /[\mathrm{O}](0.2$ and 0.8$)$ at four evolutionary times. The results in Table 6 show the high sensitivity of molecular abundances to the variation of the $[\mathrm{C}] /[\mathrm{O}]$ ratio, in particular for carbon-bearing molecules. In Table 7 the effect is minimized by mutual gas-grain interaction. Although there are still some differences in the gas-grain model, they are much lower than those in the gas-phase model.

To demonstrate explicitly the effect of raising both the $\mathrm{C}$ and $\mathrm{O}$ abundances but keeping their ratio $[\mathrm{C}] /[\mathrm{O}]$ fixed, we ran the models using two sets of $\mathrm{C}$ and $\mathrm{O}$ abundances with $[\mathrm{C}] /[\mathrm{O}]=0.2(1)$ high values of $1.410^{-4}$ and $6.110^{-4}$ and (2) low values of $6.110^{-5}$ and $3.2310^{-4}$ for $\mathrm{C}$ and $\mathrm{O}$ respectively. Other parameters remain fixed. The results are shown in Figs. 7 and 8 for $\mathrm{H}_{2} \mathrm{CO}$ and $\mathrm{CH}_{4}$. From
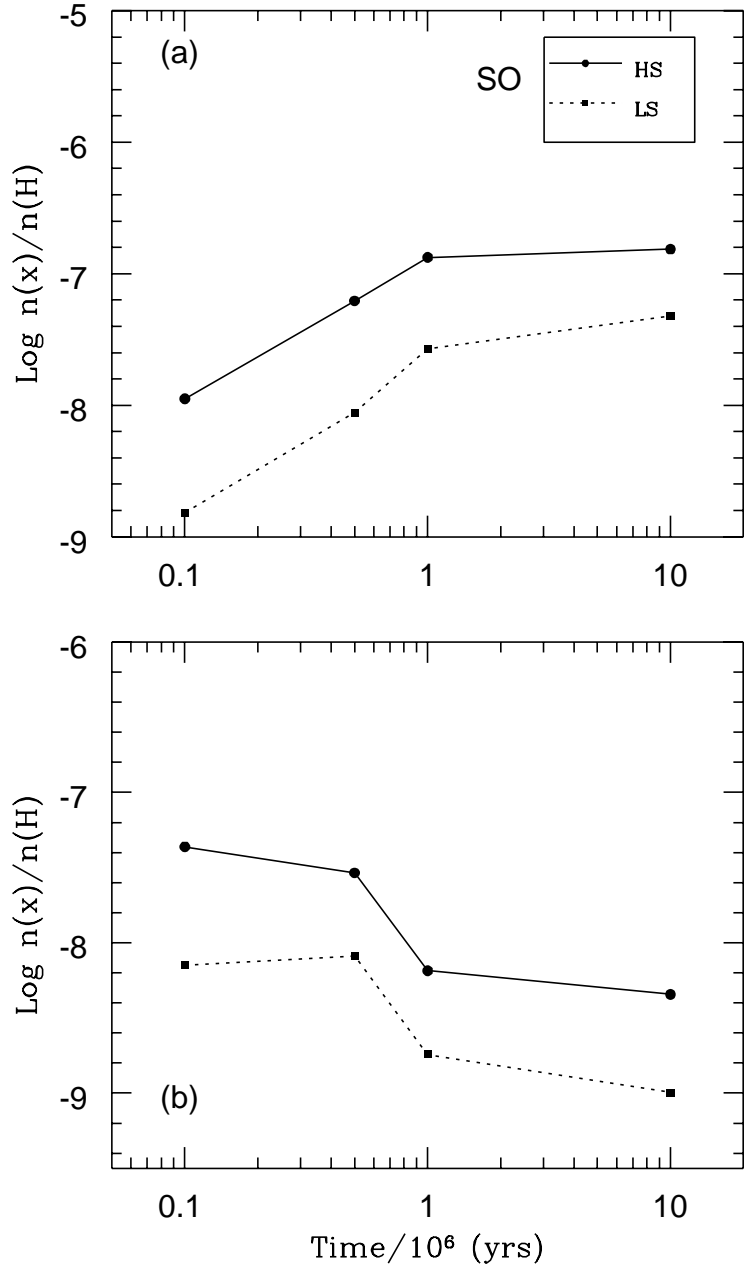

Fig. 10. The Same as Fig. 9 but for SO

these figures, we found that the differences with the two sets of $\mathrm{C}$ and $\mathrm{O}$ abundances, are very little or negligible. This is valid for both gas-phase and gas-grain models. It is interesting to conclude that the most important parameter of elemental abundance set is the ratio of $[\mathrm{C}] /[\mathrm{O}]$ rather than their explicit abundances.

We also consider the effects of using the high (undepleted) $\left(1.6210^{-5}\right)$ and the low (depleted) $\left(3.2310^{-6}\right)$ sulfur abundance on gas-phase and gas-grain models. Figures 9 and 10 show the results for CS and SO respectively. In these two figures a $[\mathrm{C}] /[\mathrm{O}]$ ratio of 0.46 has been used. As expected the SO and CS abundances are higher for high sulfur. The results of the gas-phase models do not reproduce the observed abundances (TMC-1 and L134N) very well in both the depleted and undepleted sulfur cases. For gas-grain models (b) CS is in agreement with TMC-1 $\left(10^{-8}\right)$ for the high sulfur case at $1 \mathrm{Myr}$ while for low sulfur it fits at $0.5 \mathrm{Myr}$. For L134N, model (b) agrees with the CS observed abundance $\left(10^{-9}\right)$ only at very late times (10 Myr) for the depleted sulfur case. From these results one may see that depleted sulfur is required for chemical models to fit the simple sulfur-bearing molecules. This is consistent with other models which proposed sulfur 
depletion in dense molecular clouds (e.g. Caselli et al. 1994; Kemper et al. 1999).

For chemical models of dark clouds where refractory metals are significantly depleted, we ran two models using the so-called low metal set of initial elemental abundance (see Table 1, Shalabiea et al. 1998). One for a pure gasphase chemical model and the other for a gas-grain model using both the low (0.2) and the high (0.8) $\mathrm{C} / \mathrm{O}$ ratio. Our results mainly show the same effect of varying initial $\mathrm{C} / \mathrm{O}$ ratio as in low-depleted-metal case discussed above.

\section{Conclusions}

This work confirms the vital role of the adopted set of the gas-phase elemental abundance for gas-phase models. In contrast, a variation of the carbon-to-oxygen elemental abundances in gas-grain chemical models shows little or no effect. We also conclude that the most important parameter regarding $\mathrm{C}$ and $\mathrm{O}$ is the ratio of $[\mathrm{C}] /[\mathrm{O}]$ rather than their explicit abundances for both gas-phase and gas-grain models.

For both models, early-time results show less sensitivity to changes in the $[\mathrm{C}] /[\mathrm{O}]$ ratio than those at mid or late times.

Our study also confirms the requirement of sulfur depletion for chemical models in order to reproduce the observed abundance of sulfur-bearing molecules. For further studies of the importance of the adopted set of initial elemental abundance on chemical models, we conclude that the gas-grain model, which includes both gas and solidphase chemistry, provides a more complete basis for comparison with observations.

Acknowledgements. I am very grateful to Prof. Eric Herbst for providing me the chemical network of his group at the Ohio State University and for many helpful suggestions. I further thank Prof. S. S. Hong and his group for stimulating discussions. I acknowledge the support of my visit to Seoul National University by the BK-21 program of Ministry of Education, Korea.

\section{References}

Bettens, R. P. A., Lee, H. H., \& Herbst, E. 1995, ApJ, 443, 664

Bergin, E. A., Goldsmith, P. F., Snell, R. L., \& Langer, W. D. 1997, ApJ, 482, 285

Cardeli, J. A. 1994, Science, 265, 209

Cardeli, J. A., Meyer, D. M., Jura, M., \& Savage, B. D. 1996, ApJ, 467, 334

Caselli, P., Hasegawa, T. I., \& Herbst, E. 1994, ApJ, 421, 206

Draine, B. T., \& Lee, H. M. 1984, ApJ, 285, 89

Duley, W. W., Jones, A. P., \& Williams, D. A. 1989, MNRAS, 236,709

Dickens, J. E., Irvine, W. M., \& Snell, R. L. 2000, ApJ, 542, 870

Federman, S. R., Sheffer, Y., Lambert, D. L. \& Gilliland, R. L. 1993, ApJ, 413, L51.

Genaciński, P. 2000, Acta Astron., 50, 133

Graedel, T. E., Langer, W. D., \& Freking, M. A. 1982, ApJS, 48,321
Greenberg, J. M. 1989, in Evolution of Interstellar Dust and Related Topics, ed. A. Bonnetti, J. M. Greenberg, \& S. Aiello (Amsterdam: North Holland), 5

Grevesse, N., \& Noels, A. 1993, Origin of Elements, ed. N. Prantzos, E. Vongioni-Flam, \& M. Cassé (Cambridge: Cambridge Univ. Press), 15-25

Hasegawa, T. I., Herbst, E., \& Leung, C. M. 1992, ApJS, 82, 167

Hasegawa, T. I., \& Herbst, E. 1993a, MNRAS, 261, 83.

Hasegawa, T. I., \& Herbst, E. 1993b, MNRAS, 263, 589

Herbst, E., \& Klemperer, W. 1973, ApJ, 185, 505

Herbst, E., \& Leung, C. M. 1986, MNRAS, 222, 689

Herbst, E., \& Leung, C. M. 1989, ApJS, 69, 271

Herrmman, F., Madden, S. C., Nikola, T., et al. 1997, ApJ, 481,343

Hong, S. S., \& Greenberg, J. M. 1980, A\&A, 88, 194

Kemper, C., Spaans, M., Jansen, D. J., et al. 1999, ApJ 515, 649

Langer, W. D., Graedel, T. E., Frerking, M. A., \& Armentrout, P. B. 1984, ApJ, 277, 581

Langer, W. D., \& Graedel, T. E. 1987, IAU symp., 120, Astrochemistry, ed. M. S. Vardya, \& S. P. Tarfdar (Dordrecht: Reidel), 305

Langer, W. D., William, D., \& Graedel, T. E. 1989, ApJS, 69, 241

Lee, H.-H, Roueff, G., Pineau Des Forêts, G., et al. 1998, A\&A, 334, 1047

Li, A., \& Greenberg, J. M. 1997, A\&A, 323, 566

Millar, T. J., \& Herbst, E. 1990, MNRAS, 242, 92

Ohishi, M., Irvine, W. M., \& Kaifu, N. 1992, in Astrochemistry of Cosmic Phenomena, ed. P. D. Singh (Dordrecht: Kluwer), 171

Ohishi, M., \& Kaifu, N. 1998, in Chemistry and Physics of Molecules and Grains in Space, Faraday Discussions No. 109, The Faraday Division of the Royal Society of Chemistry, London, 205

Pineau Des Forêts, G., Flower, D. R., \& Millar, T. J. 1991, MNRAS, 253, 217

Poglitsch, A., Herrmann, F., Genzel, R., Madden, S. C., et al. 1996, ApJ, 462, L43

Pratap, P., Dickens, J. E., Snell, R. L., et al. 1997, ApJ, 486, 862

Ruffle, D., \& Herbst, E. 2000, MNRAS, 319, 837

Ruffle, D., \& Herbst, E. 2001, MNRAS, 322, 770

Ruffle, D., Hartquist, W. T., Caselli, P., \& Williams, D. A., 1999, A\&A, 306, 691

Savage, B. D., \& Sembach, K. R. 1996, ARA\&A, 34, 279

Shalabiea, O. M., \& Greenberg, J. M. 1994, A\&A, 290, 266

Shalabiea, O. M., \& Greenberg, J. M. 1995, A\&A, 296, 779

Shalabiea, O. M., Caselli, P., \& Herbst, E. 1998, ApJ, 502, 652

Sofia, U. J., Cardelli, J. A., Guerin, K. P., \& Meyer, D. M. 1997, ApJ, 482, L105

Sofia, U. J., Fitzpatrick, E., \& Meyer, D. M. 1998, ApJ, 504, L47

Terzieva, R., \& Herbst, E. 1998, ApJ, 501, 207.

van Dishoeck, E. F., Black, G. A., Draine, B. T., \& Lunine, J. I. 1993, in Protostars and Planets III, ed. E. H. Levy, \& J. I. Lunine (Univ. of Arizona press), 163.

Walmsley, C. M., Pineau des Forêts, \& Flower, D. R. 1999, A\&A, 342,542

Watt, G. D. 1985, MNRAS, 212, 93

Willacy, K., \& Williams, D. A. 1993, MNRAS, 260, 635

Wilacy, K., \& Millar, T. 1998, MNRAS, 298, 562 